\title{
ARTICLE \\ Assessment of Coffea Shade Value through Comparison of Mountainous Area with Farm Land Coverage, in Arsi Gololcha District, Oromia, Ethiopia
}

\author{
Alemayehu Diriba Roba* \\ Oromia Agricultural Research Institute, Mechara Agricultural Research Center, Mechara, Ethiopia
}

\section{ARTICLE INFO}

Article history

Received: 17 August 2021

Accepted: 24 September 2021

Published Online: 9 October 2021

Keywords:

Farm lands versus mountainous areas

Ecological value of Coffea shade trees

\begin{abstract}
Coffea cultivation with shade tree is used for improving soil health, increasing coffea production, sustaining agro ecology. The study was attended in two kebele, on 36 farmers' fields, at Gololcha district of East Arsi zone. The study was intended to assess the influence of coffea shade trees on farm lands versus mountainous area. Household interviews were used to get imperative separately, i.e. from old farmers, middle age farmers and young farmers. Significant difference value was observed between farm land and mountainous area coverage. Based on this respondents' idea, before 25-30 years; the 'condition of tree coverage at mountainous' area in Arsi Gololcha district was 'medium condition' but not normal that means as deforestation of mountainous area have been starting before 30 years' time; while the condition of tree coverage at farmland area also has been starting before 30 years' time. The third respondents' idea was interpreted with the real situation of the district, that it gave us a constructive inspiration on the role of coffea shade tree to enable the farm land to be taken as regular natural forest. The existing coffea shade trees are Cordia africana followed by Erythrina abyssinica and Acacia senegal. Farmers accounted $95 \%$ of coffea shade users and $4.6 \%$ without shade users. The respondents said that even if the rainfall intensity is increasing at farmland rather than mountainous area occasionally due to shade tree effect. On the contrary side, mountainous area exposed to deforestation since the farmers have been shifting to hilly side for their livelihood dependency.
\end{abstract}

\section{Introduction: Background and Justification}

Coffea plantation with shade tree is taken as agroforestry system which is mainly viewed as significant donors of income opportunity, environmental facilities through ecofriendly well beings and as a portion of well-designed operational sceneries ${ }^{[14,15]}$. Coffea production with shade is as agroforestry scheme that casually satisfactory, cautiously viable and biologically maintainable than rising coffea without shad. A great role of shade tree is timber production which has a low management costs and it considered as a 'exchangeable account' that can be comprehended at times of low prices or failure of the fundamental crop yields ${ }^{[3]}$. The integration of trees with agricultural sectors to be taken as an agro-forestry scheme which takes probable towards improve biodiversity, improve soil richness, decrease soil destruction problem, advance water eminence, rise aesthetics value and

*Corresponding Author:

Alemayehu Diriba Roba,

Oromia Agricultural Research Institute, Mechara Agricultural Research Center, Mechara, Ethiopia;

Email: alemayhudiriba@gmail.com 
requisition impressive carbon ${ }^{[8,9,12,16]}$. Coffea production with shade tree consumes remained healthy accepted due giving comforts and welfares as to be agro-forestry schemes through assortment of spatial and temporal arrangements ${ }^{[7]}$.

Agro-ecosystems come from agroforestry which deliver significant properties and facilities that donate towards anthropological relief, financial advance and poverty mitigation. Agro-forestry, currently, nearby a countless deal of attention trendy provided that monetary welfares towards property-owners. Coffea production with coffea shade tree is one of the main agro-forestry schemes and the farmers with land use achievement that stand-in respected conservational amenities headed for anthropological residents in addition for agriculturalists originating revenue opportunity as of their customary invention system ${ }^{[4]}$. Coffea production with shade trees has a great role in providing environmental facilities and improving sustainable bio-diversity safeguarding ${ }^{[10]}$. Therefore, worldwide have to be focused on payment for environmental amenities and coffea guarantee schemes so as to deliver incentives towards coffea growers thereby to produce organic quality coffea ${ }^{[11]}$.

In many parts of coffea growers have been used versatile trees as shade, shelterbelt and windbreaks to avert coffea vegetation as of extreme sun and extraordinary illnesses ${ }^{[6]}$. Organic coffea production increases annual income of producers' and GDP of countries. Coffea dependent countries that containing Ethiopia; disseminate coffea product about more than 160 countries those as long as a source of revenue intended for many individuals ${ }^{[5]}$.

In Africa, Ethiopia is the chief principal arabica coffea producer among 25 countries, and the $5^{\text {th }}$ of worldwide with the form of home garden coffea production system by small scale farmers ${ }^{[1]}$. Subsequently $25 \%$ of Ethiopian population depends on coffea product through producing, processing, distributing, exporting and also consuming, as well as $25 \%$ of country's GDP based of coffea product ${ }^{[10]}$.

In Ethiopia, the driving force of coffea production in the form of home garden Coffea is land shortage. The place where coffea growing areas have been occupied with highly populated and this is resulted for farm land shortage in the country. For example; in the study area, cultivable land shortage has been rising due to population size increment. So the land owners exposed to have owned a small piece of land.

However, on that limited cultivable land; enable the farmers merely alternative to use coffea plantation with shade trees on what they have had at all specific farm land considerately rather than cereal crop utilize which is needed extensive farm land. So the agriculturalists implemented with concentrated endowment of coffea manufacture with shade tree invitation on their specific farm land as their usual practice in Gololcha district. The concentrated functions of shade trees are revealed as if natural woodland at coffea farmstead terrestrial only. In the discordant of this, hilly areas which were out of coffea plantation have been continuing deforestation problem. This problem occurred due the societies have been cultivating towards mountainous sideway for their living reliance is exactly reflecting in Gololcha district.

The study areas were designated due to nomination of district with pure biological coffea production as a result of shade tree effect on coffea farm lands. Therefore; the study was carried out to assess farmers' perception on coffea shade value through comparison of mountainous area exposure with farm land coverage, and also to conscious consideration of farmers, administration and further shareholders headed for guarantee and incentive approach for organic coffea growers.

\section{Materials and Methods}

\subsection{Explanation of the Investigation Extent/ Location}

Rendering to Oromia existing framework (2006), Gololcha district (Figure 1) is solitary of the vicinities originate in Arsi zone, Oromia regional state-owned of Ethiopia. The district is traced situated $307 \mathrm{~km}$ South East of Addis Ababa that capital city of Ethiopia. The topographical straight of the extent is between $08^{\circ} 00^{\prime} 0^{\prime \prime}$ and $08^{\circ} 37^{\prime} 00^{\prime \prime} \mathrm{N}$ and $40^{\circ} 00^{\prime} 00^{\prime \prime}$ and $40^{\circ} 29^{\prime} 00^{\prime \prime} \mathrm{E}$.

\subsection{Climate and Rainfall}

The study area experiences by mean annual and monthly minimum and maximum temperature were 15 and $27^{\circ} \mathrm{C}$, correspondingly; and takes mean annual and monthly precipitation (Figure 2) is $550 \mathrm{~mm}$ in the year of 2015 cropping period. The seven years statistics of mean annual and monthly rainfall (Figure 3) in the study area are $703 \mathrm{~mm}$ minimum in the year of 2012 and $1486 \mathrm{~mm}$ maximum in the year of 2013, correspondingly; which illustrate the extent partaking a bimodal precipitation nature.

\subsection{Land-use/Land-cover Change}

Coffea plantation is solitary of the foremost crops in the constituency. Production of Khat and coffea are imperative currency product. Out of the total area of the constituency, $20.6 \%$ is cultivable land, $21.7 \%$ is meadowland, $27 \%$ is forest and shrubs, and the left over $30.7 \%$ is well thought 


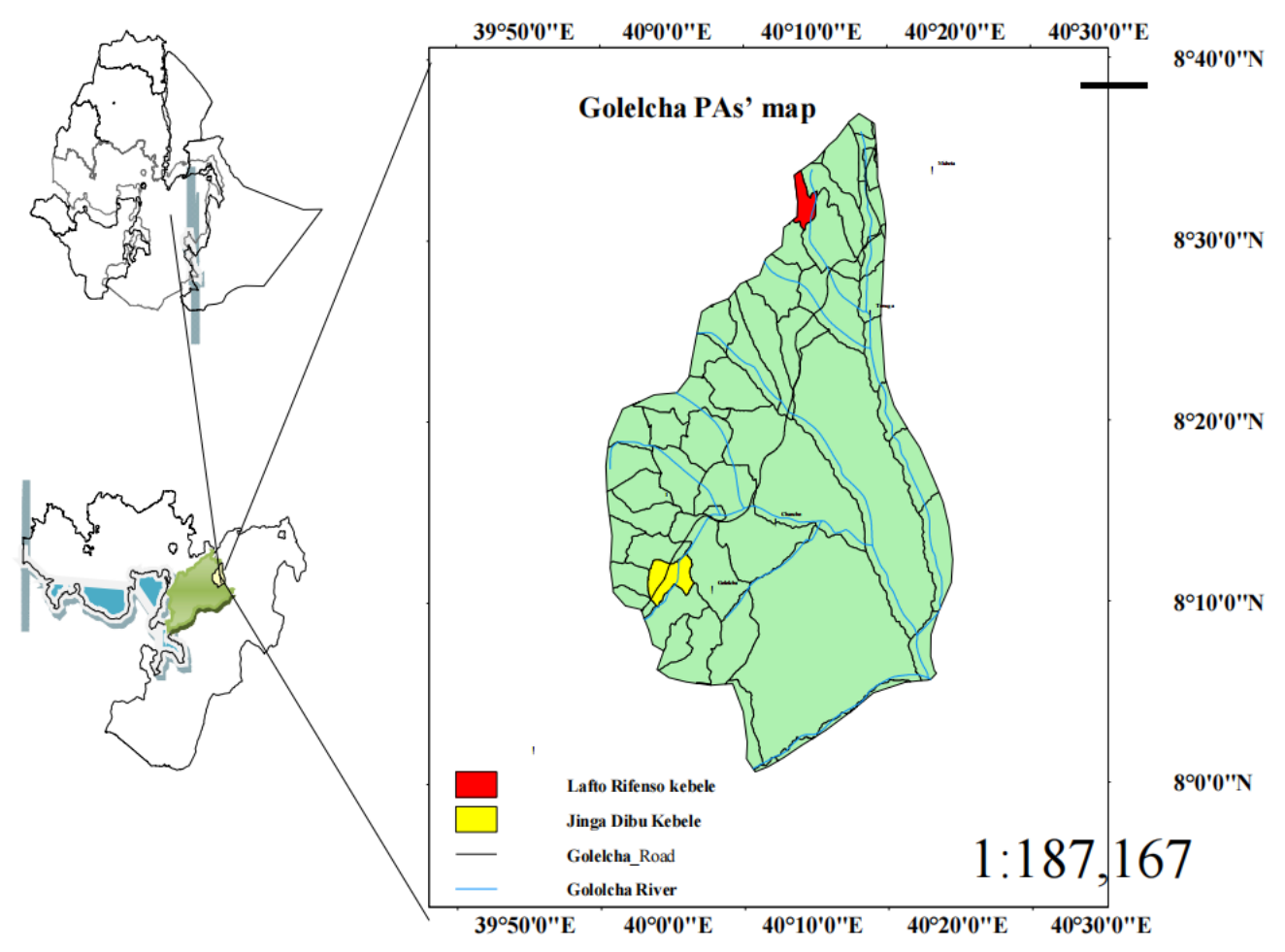

Figure 1. Specific location of the studies area

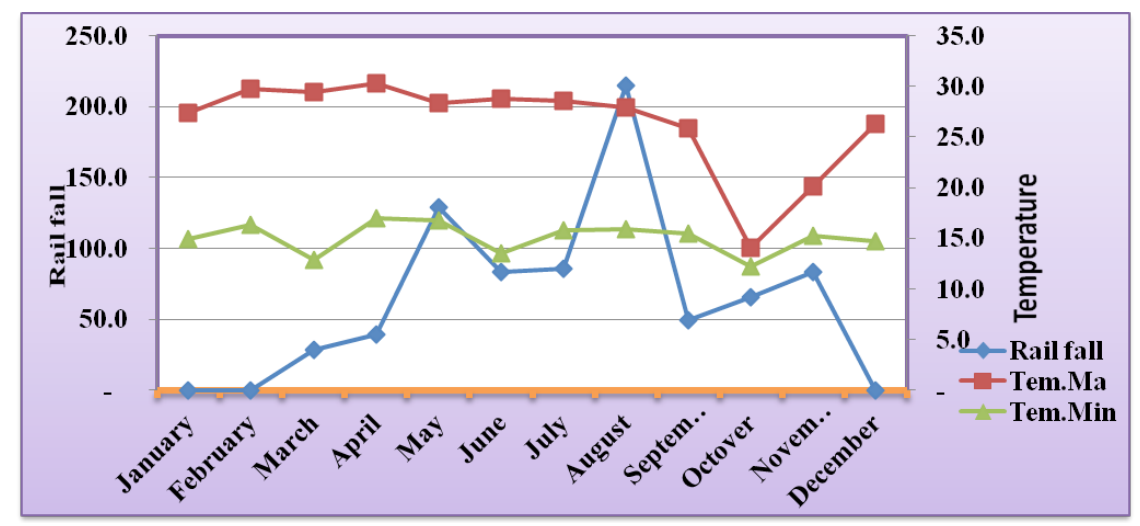

Figure 2. Rain fall and Temperature data of Arsi Gololcha district, 2015 GC

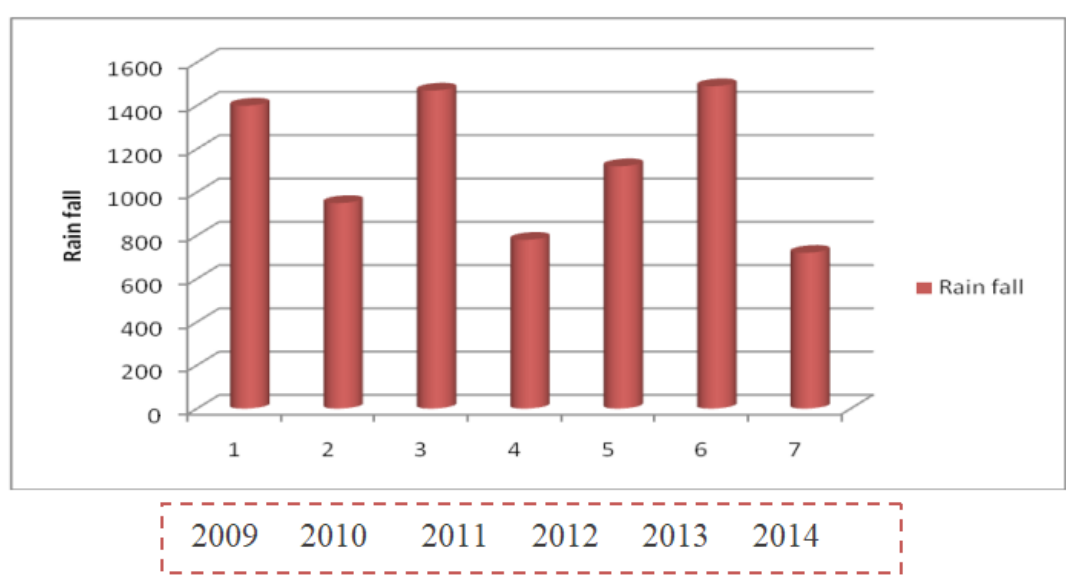

Figure 3. Seven years only (2009-2015GC) Precipitation statistics of Arsi Gololcha district 
of marshy, hilly or then impracticable part. Gololcha has appraised inhabitants with concentration of 94.7 individuals per square kilometer. As of an entire part of $1,818.120$ square kilometers, and the overall soil of the district cambisol which is the superlative for agrarian persistence that according to Oromia living profile of 2006.

\subsection{Location Assortment}

The research was directed in Gololcha District at two PA (Jinga dibu and Lafto rifenso). As of the designated PA, three settlements were allocated commencing each PA along the boundary of mountainous area. Then the study was under taken on six farmers as of every settlement. To do this route, humble investigation review was genuine in order to handpick settlements and agriculturalist's meadow for supplementary inquiry.

\subsection{Exploration Appraisal and Agriculturalist's Field Assortment}

The reconnaissance survey had been processed on six farmers in each village as replication based on field quality which was the best of all with different physical observation for all study purposes in each village across PAs. The agriculturalist's meadow was occupied, as a demonstrative crosswise PAs ended site with comparable controlling trial; advancement and gradient were measured for together unshaded and shaded coffea cultivated area, plus the concerned and subjugated of coffea shade plants in the areas were well considered.

\subsection{Data to be Collected}

Recognizance survey results of farmers' perception concerning to coffea shade value on farmlands versus mountainous areas and the kind of shade trees used were collected.

\subsection{Farmers Assortment}

The schoolwork was conducted in Gololcha district at two PA. As of the designated PAs, three settlements were allotted starting every PA along the border of mountainous area. Then the study was under taken on six farmers as of each settlement. To do this route, modest investigation survey and questioners were smeared in command to get overall answers of questioners. The results of the surveys and questioners were based on farmers' age category $(15-25,25-45$ and $>45$ age). The farmers responded to the subject concerning to coffea shade utility related to environmental and ecological condition.

Exposure of farm land coverage versus mountainous area and the relative abundance of coffea shade tree in the district were identified. Six farmers were assigned for each age category as respondent in each village, those (18 farmers from each PA and 36 farmers across PAs) were taken differently, and they responded the subject that "the condition of tree coverage at mountainous versus farm land area" during 15-25 years old of each respondent in order to answer the queries based on the questioners.

\subsection{Data Analysis}

The collected data from key informant and household interviews were summarized in narrative form that presented and analyzed descriptively.

\section{Results and Discussion}

\subsection{Farmers' Knowledge Approach on Coffea Shade Value in the District}

The consequence of hands-on investigation approaches and the appreciation on the protagonist of indigenous acquaintance in the strategy and administration of agro forestry schemes have been universally quantified. This schoolwork originated that agriculturalists have a very clear, explanatory, and coherent way of understanding the miscellaneous natural progressions that occurred in their coffea farmsteads and how these progressions narrate to coffea manufacture, delivery of ecological unit amenities and including biodiversity maintenance. They evidently accustomed how coffea production with shade tree is imperative point for ecosystem service thereby natural resources management in accordance within their plantations. Agriculturalists constantly identified that coffea productivity, ecosystem services, and biodiversity preservation are stabled due to the existence, profusion, assortment and executive of shade tree sorts. They figure their own shade tree well-designed arrangements correlated to the delivery of ecofriendly facilities and income opportunity grounded on shade tree features specially on coffea farmers which is, as if natural forest instead of mountainous area was happened before.

The respondents reasoned that trees are reserved by agriculturalists inside coffea plantations; because of their interactions with coffea plants that provide environment amenities ${ }^{[4,13]}$. The earlier endowments deliver a base for more demanding investigations of the natural surroundings and degree of coffea cultivators' friend.

\subsection{Farmers' Response on Coffea Shade Value in the District}

Farmers in different age categories responded to the 


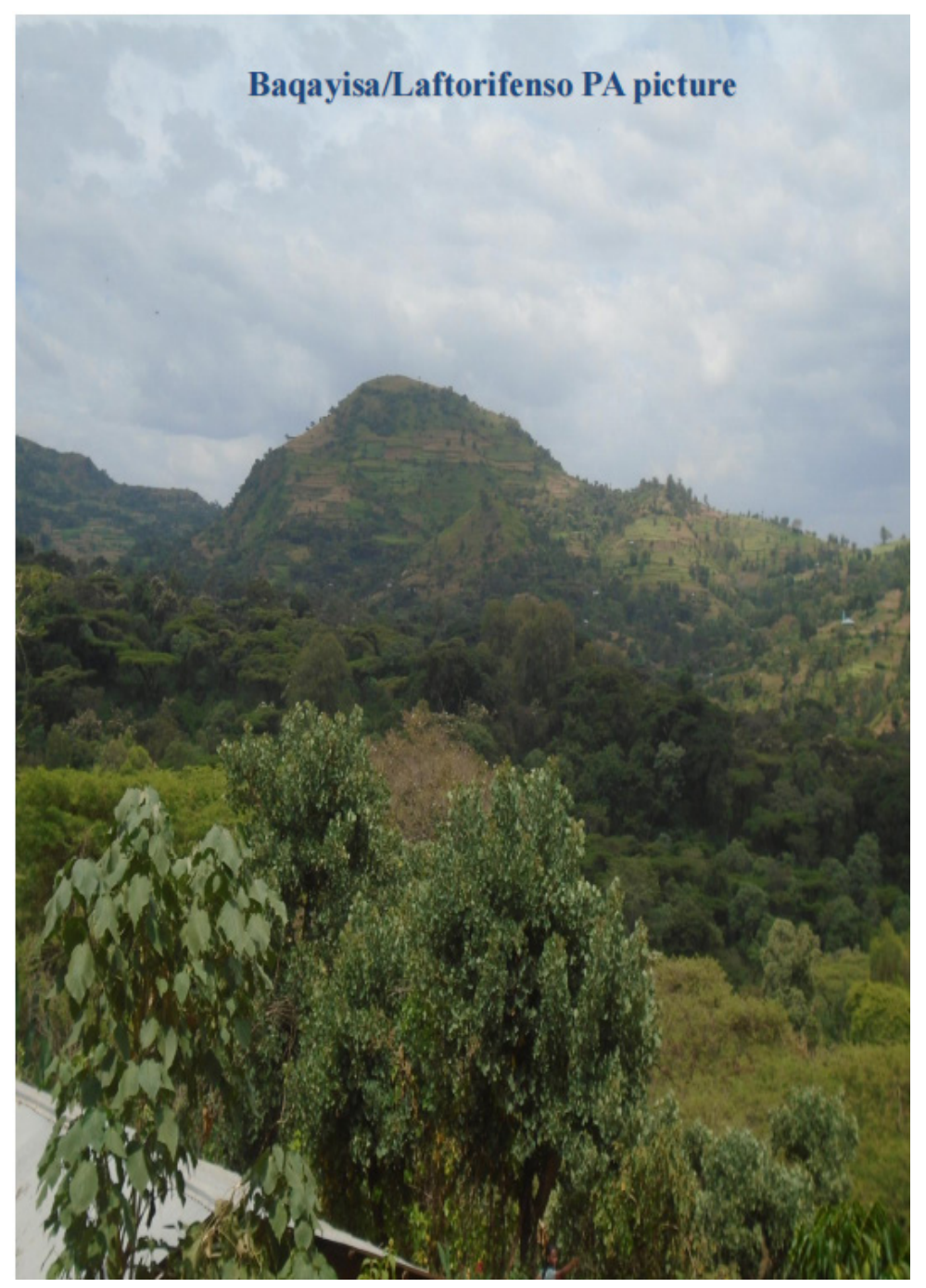

Figure 4. Farmland of coffea plantation versus with non-farmland on the top of mountain area

question, what was the condition of tree coverage at mountainous area was like, the respondents answered the following. 'Decreasing condition,' was given by the first age category, 'Medium condition', was given by the second age category and 'Increasing condition' was given by the third age category. Concerning to what was the condition of tree coverage on farm lands like; again the respondents were answered the questions saying the following. 'Increasing condition', was given by the first age category, 'Increasing condition' was given by the second age category and 'Decreasing condition' was given by the third age category during 15-25 years old of each respondent respectively (Table 1 ).

These results indicated that the third age category (elder) when they were young, there was no deforestation at mountainous area while deforestation was at farm land area. The opposite of the third age category's answerers were responded by the first age category of respondents that there was deforestation at mountainous area while there was no deforestation at farm land area. These ideas reflect the present condition of Gololcha district.

The second age group respondents' thought were similar to the first age group respondents' thought and opposite of the third age group respondents' idea on the 'condition of farm land tree coverage' during their 15-25 years old but the 'condition of mountainous tree coverage 'area was not share neither the first nor the third age group respondents' idea. Based on this respondents' idea, before 25-30 years, the 'condition of tree coverage at mountainous' area in Arsi Gololcha district was 'medium condition' but not normal that means as deforestation of mountainous area have been starting before 30 years time while the condition of tree coverage at farmland area also has been starting before 30 years time. The third respondents' idea was interpreted with the real situation of the district, that it gave us a constructive inspiration on 
Table 1. Summary of Reconnaissance survey result at Laftorifenso and Jingadibu PA

\begin{tabular}{|c|c|c|c|c|c|c|c|c|c|c|c|c|c|c|c|c|c|}
\hline \multirow{2}{*}{\multicolumn{2}{|c|}{$\begin{array}{c}\text { No. of farmers } \\
\text { With age }\end{array}$}} & \multirow{2}{*}{$\begin{array}{l}\text { Tree cover- } \\
\text { age at farm } \\
\text { land during } \\
15-25 \text { years } \\
\text { old of } \\
\text { respondents }\end{array}$} & \multirow{2}{*}{$\begin{array}{c}\text { Tree } \\
\text { coverage at } \\
\text { protected } \\
\text { area during } \\
15-25 \text { years } \\
\text { old of } \\
\text { respondents }\end{array}$} & \multicolumn{2}{|c|}{$\begin{array}{c}\text { Aver- } \\
\text { age land } \\
\text { holding for } \\
\text { coffea in } \\
\text { ha }\end{array}$} & \multicolumn{2}{|c|}{$\begin{array}{l}\text { Average land } \\
\text { holding for } \\
\text { cereals in ha }\end{array}$} & \multicolumn{2}{|c|}{$\begin{array}{c}\text { Coffea } \\
\text { with shade } \\
\text { users } \%\end{array}$} & \multicolumn{2}{|c|}{$\begin{array}{c}\text { Coffea } \\
\text { without } \\
\text { shade } \\
\text { users } \%\end{array}$} & \multicolumn{2}{|c|}{$\begin{array}{c}\text { Cordia } \\
\text { shade } \\
\text { users for } \\
\text { coffea } \%\end{array}$} & \multicolumn{2}{|c|}{$\begin{array}{c}\text { Erythrina } \\
\text { shade users } \\
\text { for coffea \% }\end{array}$} & \multicolumn{2}{|c|}{$\begin{array}{c}\text { Other shade } \\
\text { tree users for } \\
\text { coffea } \%\end{array}$} \\
\hline & & & & LPA & JPA & LPA & JPA & LPA & JPA & LPA & JPA & LPA & JPA & LPA & JPA & LPA & JPA \\
\hline $1^{\text {rst }}$ Age & $\begin{array}{l}\text { 6farmers } \\
<25 \text { year }\end{array}$ & Increasing & Decreasing & 0.35 & 0.25 & 0.15 & 0.125 & 97 & 98 & 3 & 2 & 60 & 48 & 23 & 26 & 17 & 26 \\
\hline $2^{\text {snd }} \mathrm{Age}$ & $\begin{array}{c}6 \text { farmers } \\
<45 \text { year }\end{array}$ & Increasing & Medium & 0.7 & 0.75 & 0.4 & 0.25 & 93 & 96 & 7 & 4 & 50 & 50 & 35 & 31 & 15 & 19 \\
\hline $3^{\text {rd }}$ Age & $\begin{array}{c}6 \text { farmers } \\
<65 \text { year }\end{array}$ & Decreasing & Increasing & 0.65 & 0.6 & 0.2 & 0.125 & 93 & 95 & 7 & 5 & 40 & 46 & 32 & 25 & 28 & 29 \\
\hline Average & & - & - & 0.6 & 0.5 & 0.25 & 0.16 & 94 & 96 & 5.6 & 3.6 & 96 & 48 & 3.6 & 27.3 & 20 & 25 \\
\hline
\end{tabular}

*LPA=Lafto-rifenso PA, JPA=Jinga-dibu PA, ha=hectare, PA=Peasant Association

the role of coffea shade tree to enable the farm land to be taken as regular natural forest in steady of mountainous area before.

According to description of Arsi Gololcha district with (Oromia livelihood profile, 2006), there is a problem of farm land shortage due to over population. This idea is true as to be understood from the respondents' answerer and the surviving prerequisite. Anon (2001) reported four categories of coffea manufacture schemes in Ethiopia: Woodland coffea (10\%), Semi Woodland coffea (35\%), Garden coffea $(50 \%)$ and Estate farm coffea $(5 \%)$. Arsi Gololcha district employed; garden coffea production system by small scale coffea growers. As a shortage of farm land in the district, farmers use multi-purpose utility of coffea shade tree for their livelihood dependency through coffea production thereby as fuel wood, feed, furniture, windbreak and shelter of coffea plant in specific farm land rather than cereal crops utilize which needs extensive farm lands.

\subsubsection{Farmers' Problem}

Average lands holding by the first age categories were 0.15 ha for cereal crops and 0.35 ha for coffea production. Average land holdings by the second age categories were 0.4 for cereal crops and 0.7 ha for coffea production. Average land holdings by the third age categories were 0.2 ha for cereal crops and 0.65 ha for coffea production at Ginga-dibu PA while at Lafto-rifenso PA, average land holding by the first age categories were 0.125 ha for cereal crops and 0.25 ha for coffea production. Average lands holding by the second age categories were 0.25 ha for cereal crops and 0.75 ha for coffea production. Average lands holding by the third age categories were 0.125 ha for cereal crops and 0.6ha for coffea production (Table 1). This result implies that at both PA, there is severe of farm land problems for both coffea and cereal crops across PAs.

\subsubsection{The Kind of Coffea Shade Used}

The most familiar coffea shade plants at the district are Cordia africana followed by Erythrina abyssinica and Acacia senegal, it sues as timber, fodders, fuels, etc. at both PA, respectively. Almost all farmers accounted 96\% of coffea shade users and 3.5\% without any shade users were observed in Lafto-rifenso PA. In Ginga-dibu PA, thus $94 \%$ coffea shade users, $5.6 \%$ without any shade tree users were identified. So farmers used Cordia africana shade tree is $48 \%$, Erythrina abyssinica shade tree is $27.3 \%$ and other shade tree is $25 \%$ in Lafto-rifenso PA. In Jinga-dibu PA, farmers used Cordia africana shade tree is $50 \%$, Erythrina abyssinica shade is $30 \%$ other shade tree is $20 \%$ (Table 1). As a result of this, $90 \%$ of the farm land in the district was covered by coffea plantation with shade tree application. The respondents have been truly reflecting that even if the rainfall intensity is increasing at farmland rather than mountainous area occasionally. On the contrary side, mountainous area exposed to deforestation since the farmers have been shifting to mountainous sideways for their living reliance. Generally, farmers have to be used the best agroforestry practice based on the value of shade tree for coffea plantation as well as for other utilities on what they have had a limited farm land with the recommended technology.

\section{Conclusions and Recommendations}

In Gololcha district; coffea grower agriculturalists have a treasure of knowledge with coffea gardening. Agriculturalists recognize that the dynamics disturb coffea production as well as how to increase the delivery of biota amenities within coffea farms. All age groups comprehend 
with fact that the protagonist of coffea shade trees in together coffea production and delivery of other biota amenities. Recurrently; agriculturalists revealed trade-offs amongst biota amenities' delivery and production. The other point to be considered the value of coffea shade is soil development and avoidance soil destruction on farm lands. This is perceived synergistically with farm land production, while biodiversity upkeep is the opposite. These much of native acquaintance should be confirmed.

Ethiopia is agricultural dependent by periodic precipitation coincidental. Planting of shade trees on agricultural land, it is to be an agro-forestry exercises that to sustain environmental biodiversity, increase production and well ecological condition. Nevertheless, the value of shade tree; on soil fruitfulness and coffea productivity have not been broadly appraised and accurately renowned. Key informants and relevant households were used based on their age group. The information obtained from the survey, included problem identification and specially deforestation at mountainous area and afforestation of farm-lands.

In this assessment, the difference between Erythrina abyssinica and Cordia africana shade trees found higher significant with almost all farmers' perception. So that the governance of shade type in the coffea farm was primarily due to its financial worth that agriculturalists favored Cordia africana rather than environmental amenities. It concealed about $60 \%$ and $48 \%$ of farm-land in Laftorifenso and Jinga-dibu PA; while Erythrina abyssinica covered about $23 \%$ and $26 \%$ of farm-land in Lafto-rifenso and Jinga-dibu PA, respectively.

In conclusion, Gololcha district is deserved an assurance as they are model agriculturalists. That integration of coffea with shade tree can be principal to be originator of sustainable agriculturalists, organic coffea manufacturers and sponsor of climatic resilience. They deserve a certification because they can to be a model for other farmers with resilience to climate change and improved their livelihoods as well as they are sustainable producer of organic coffea production. Many writers positively articulated for this kind of views that certification approach should be advanced for organic coffea cultivators. The other point to be considered is fair traders had to be delivered different price premium which can be offer farmers distinct economic incentives. So that farmers can have a unique ecological standard in order to sustain coffea production with shade trees ${ }^{[14]}$.

Accessibility of shade tree was presently being experienced in the area meaningfully with amended coffea manufacture, soil fruitfulness; ecological value and living of the people with vary of utility. Consequently the district's farmers have to be given recognized that the shade trees combination in the agricultural scheme is appreciated and should be encouraged by relevant stakeholders to be regarded as exemplar for farmers in neighboring districts who had been producing coffea without shade. This practice should be promoted in most districts of Hararghe that where coffea farmlands nearly wiped out and have been replacing with Khat.

\section{References}

[1] AfDB, 2010. Boards of Directors of the African Development Bank and the African Development Fund. Covering the period January 1 to December 31, 2010.

[2] Albertin, A., Nair, P., 2004. Farmers' perspectives on the role of shade trees in coffea production systems: an assessment from the Nicoya Peninsula, Costa Rica. Human Ecology 32 (4).

[3] Calvo, G. and Platen. H. 1996. Cacao-laurel-plátano. Costosy beneficios financieros. Serie Técnical Informe Técnico. No.264.CATIE, Turrialba, CostaRica.

[4] FAO State of Food and Agriculture Report, 2007. FAO Economic and Social Development Department,CorporateDocumentRepository.http:// www. fao.org/docrep/010/a120e/a1200e00.htm> (accessed 27.11.09).

[5] ICO. 2001. International Coffea Organization. The Global Coffea Crisis: A Threat to Sustainable Development. URL: www.ico.org.

[6] Idol, T. and Youkhana, A. 2010. Managing Shade Trees for Coffea Can Benefit the Soil. Hānai 'Ai / The food Provider. College of Tropical Agriculture and Human Resources, University of Hawai, Manoa.

[7] Izac, A., 2003. Economic aspects of soil fertility management and agroforestry practices. In: Schroth, G., Sinclair, F.L. (Eds.), Trees, crops and soil fertility: concepts and research methods. CABI, Wallingford, UK, p. 464.

[8] Garrett, H., McGraw, R., 2000. Alley cropping practices. In: Garrett, H., Rietveld, W., Fisher, R. (Eds.), North American Agroforestry: An Integrated Science and Practice. ASA, Madison, pp. 149-188.

[9] Garrity, D., 2004. Agroforestry and the achievement of the millennium development goals. Agroforestry Systems 61, 5-17.

[10] Moguel, P., Toledo, V., 1999. Biodiversity conservation in traditional coffea systems of Mexico. Conservation Biology 13 (1), 9-25.

[11] LeCoq, J.F., Soto, G., González, C., 2011. PES and Eco-labels: a comparative analysis of their limits and opportunities to foster Environmental Services provision. In: Rapidel, B., DeClerck, F., Le-Coq, J.F., 
Beer, J. (Eds.), Ecosystem Services From Agriculture and Agroforestry: Measurement and Payment. Earthscan, London, UK, pp. 237-264.

[12] Nai Nair, P., Kumar, B., Nair, V., 2009. Agroforestry as a strategy for carbon sequestration. Journal of Plant Nutrition and Soil Science 172, 10-23.

[13] Soto-Pinto, L., Perfecto, I., Castillo, H., Caballero, N., 2007. Shade effect on coffea production at the northern Tzeltal zone of state of Chiapas, Mexico. Agriculture, Ecosystems and Environment 80, 61-69.

[14] Perfecto, I., Vandermeer, J., 2006. The effect of an ant-hemipteran mutualism on the coffea berry borer (Hypothenemus hampei) in southern Mexico. Agriculture, Ecosystems and Environment 117, 218-221.

[15] Harvey, C., Medina, A., Merlo Sánchez, D., Vilchez, S., Hernández, B., Sáenz, J., Maes, J.M., Casanoves, F., Sinclair, F.L., 2006. Patterns of animal diversity in different forms of tree cover in agricultural landscapes. Ecological Applications 16 (5), 1986-1999.

[16] Williams-Guillén, K., Perfecto, I., Vandermeer, J., 2008. Bats limit insects in a Neotropical agroforestry system. Science 320 (70), 5872. 